\title{
Cognitive development of lead-exposed children near Borella junction
}

\author{
Manouri P Senanayake ${ }^{1}$, S P Sumanasena ${ }^{2}$ \\ Sri Lanka Journal of Child Health, 2003; 32: 15-7
}

(Key words: Cognitive development, lead-exposed children, Colombo)

\begin{abstract}
Objective To study cognitive development of children exposed to lead in Colombo.

Design A cross-sectional descriptive study.

Setting City of Colombo, near Borella junction.

Study population 50 children with blood lead levels ranging from $1.6-13.5 \mu \mathrm{g} / \mathrm{dl}$.
\end{abstract}

Method Risk factors for lead exposure were assessed using an interviewer administered questionnaire. Development and cognitive abilities of the children were assessed.

Results Close proximity to traffic congested highways and surface water drains were common to entire cohort. Purchase of food from roadside vendors was found in all children. $78 \%$ children residing in area $>10$ years and $66 \%$ children attending school for $>5$ years had a below average developmental score. Blood lead levels correlated significantly with increasing age and length of stay in this area.

\section{Introduction}

Sri Lanka does not have a screening programme for lead exposure. However, concerns have been expressed regarding blood lead levels of children living in the city of Colombo ${ }^{1}$.

Long term exposure to even low levels of lead affects cognitive development of children ${ }^{2,3}$. We report on the cognitive development of a cohort of lead exposed city dwelling children and compare it with their duration of stay in this traffic congested area and their blood lead levels.

\section{Objective}

To study the cognitive development of children exposed to lead in Colombo.

\footnotetext{
${ }^{1}$ Senior Lecturer in Paediatrics, Faculty of Medicine, University of Colombo, ${ }^{2}$ Demonstrator, Department of Paediatrics, Faculty of Medicine, University of Colombo.
}

(Received on 20 November 2002)

\section{Design}

A cross-sectional descriptive study.

\section{Study population}

The study population consisted of 50 apparently healthy children aged 1-15 years who had lived since birth within a radius of $0.5 \mathrm{~km}$ from Borella junction in the city of Colombo. Their blood lead levels ranged from $1.6-13.5 \mathrm{mg} / \mathrm{dl}$ at the time of study. Mean blood lead levels in relation to age were:

$$
\begin{array}{rr}
<5 \text { years } & 4.3 \pm 1.9 \mathrm{mg} / \mathrm{dl} \\
5-10 \text { years } & 5.5 \pm 1.3 \mathrm{mg} / \mathrm{dl} \\
10-15 \text { years } & 6.7 \pm 1.8 \mathrm{mg} / \mathrm{dl}
\end{array}
$$

\section{Method}

The presence of environmental and behavioural risk factors for lead exposure were assessed using an interviewer administered questionnaire (Table 1).

Table 1

Risk factors for lead exposure in children

\section{Environmental risk factors}

Vehicular congestion

Lead lined water tanks

Lead piping

'Old' paint in homes

Proximity of home to road

Surface water drains

Lead-linked parental occupations

Lead-linked industries

\section{Behavioural risk factors}

Purchase of edibles from roadside vendors

Food preparation in glazed pottery/ceramics

Roadside playing

Chewing or sucking pencils

Habitual hand-mouth activities

Use of traditional cosmetics ('surma')

The development and cognitive abilities of all 50 children in study population were assessed. Modified 
Griffith Development scales were used to assess 1-6 year olds. Gross motor, eye hand co-ordination, hearing and speech, social skills and performance were assessed to calculate developmental quotients as a percentage of:

developmental age in months

chronological age in months

Children over 6 years had their number and reading skills assessed using age appropriate school textbooks and a validated scoring system ranging from 0 6. Ability to read a paragraph, identified from second lesson of prescribed text-book, was judged 'good', 'correct but hesitant', 'incorrect' or 'unable' and a score of 3, 2, I or 0 awarded accordingly. The last sum in each of the first three lessons was tested and one mark awarded for each correct answer. Adequate time was provided to think, work and write the answers. Final grading score comprised a combination of the reading and number scores, ranging from 6 to 0 . A combined score of 6 or 5 was rated above average', a score of 4 or 3 'average' and a score $0-2$ 'below average'. Scores obtained were compared with chronological ages and blood lead levels.

\section{Results}

The children were all of poor socioeconomic backgrounds and lived in an environment with risks of lead exposure. Close proximity to traffic congested highways and surface water drains were common to entire cohort studied. Purchase of food from roadside vendors was found in all 50 children.

School aged children were from three different schools in locality. We did not find behavioural or neurological abnormalities. Developmental/cognitive assessments showed the following results:

Of 13 children residing in this area for $>10$ years, 10 (78\%) had a below average developmental score. Children who lived 5-10 years in the area had significantly higher developmental scores $(\mathrm{p}<0.01)$.

In relation to number of years of schooling, $66 \%$ of children who attended school for $>5$ years had a below average developmental score whereas $80 \%$ of children who attended school for $<5$ years had above average developmental scores $(\mathrm{p}>0.05)$.

Decrease in cognitive scores correlated significantly with increasing age and length of stay in area. Blood lead levels also showed a significant correlation with age and duration of stay in area ${ }^{1}$.
Hand to mouth activities and playing by roadside or in parks adjacent to busy highways were behavioural risk factors that related significantly with below average developmental scores.

\section{Discussion}

Children have a higher lung deposition and gut absorption rate of lead than adults. They inhale a larger volume of air per unit body weight and hence are more vulnerable to lead in air.

Area of residence of these children was in close proximity to a junction which was under construction at time of this study. 5 roads with heavy traffic congestion met at this junction.

$90 \%$ of lead in city air is from vehicles that burn leaded petrol $^{4,5}$. Air pollution contaminates soil and lead persists in environment for a considerable period of time even after removal of lead from petrol.

Damage caused to developing central nervous system by lead is well known ${ }^{3,6}$. The cohort of children we studied all had assayable lead levels in their blood as estimated by Occupational Hygiene Division of Department of Labour, Colombo using atomic absorption spectrometry ${ }^{1}$. Our finding that developmental and cognitive scores had decreased with increasing age may have contributory factors apart from lead, since cognition is affected by many variables such as social, educational, environmental and medical factors. For example even noise levels around schools influence cognition $^{7,8 .}$

However, based on our finding that cognitive abilities were adversely affected in socially disadvantaged children attending three separate schools in an area in the city with heavy traffic congestion; and that it correlated to length of stay in area; we recommend closer scrutiny on effects of lead on cognitive development in urban children in Sri Lanka. Risk of lead exposure remains even after leaded petrol is discontinued. We hope the public health authorities will undertake screening programmes for excess lead in children because effects of lead are neither immediate nor obvious.

\section{References}

1. Amaratunge S, Sumanasena S P, Hubert H D M, Senanayake Manouri P. Blood lead levels of children living near Borella junction. Ceylon Medical Journal 2001; 46:111.

2. Good M 1. Long term effects of exposure to low doses of lead in childhood. New England Journal of Medicine 1991; 324:415-8. 
3. Needleman H I, Schell A, Bellinger D, Levinton A, Allred E N. Long term effects of exposure to low doses of lead in childhood, an 11 year follow up report. New England Journal of Medicine 1992; 322: $83-8$.

4. Read R C, Green M. Internal combustion and health. British Medical Journal 1990; 300: 761-2.

5. Romieu I. Urban air pollution in Latin America and the Carribean: Health Perspectives. World Health Statistics Quarterly 1990; 43:153-67.
6. Fulton M. Influence of blood lead on ability and attainment of children in Edinburgh. Lancet 1987; 2:1221 -6.

7. Sanz S A, Garcia A M, Garcia A. Road traffic noise around schools: a risk for pupils/ performance? International Archives of Occupational and Environmental Health 1997; 65(3): 205-7.

8. Lane S R, Meechara W C, Jet noise at schools near Los Angeles International Airport. Journal of Acoustical Society of America 1974; 56:127-31. 



\title{
Cognitive development of lead-exposed children near Borella junction
}

\author{
Manouri P Senanayake ${ }^{1}$, S P Sumanasena ${ }^{2}$ \\ Sri Lanka Journal of Child Health, 2003; 32: 15-7
}

(Key words: Cognitive development, lead-exposed children, Colombo)

\begin{abstract}
Objective To study cognitive development of children exposed to lead in Colombo.

Design A cross-sectional descriptive study.

Setting City of Colombo, near Borella junction.

Study population 50 children with blood lead levels ranging from $1.6-13.5 \mu \mathrm{g} / \mathrm{dl}$.
\end{abstract}

Method Risk factors for lead exposure were assessed using an interviewer administered questionnaire. Development and cognitive abilities of the children were assessed.

Results Close proximity to traffic congested highways and surface water drains were common to entire cohort. Purchase of food from roadside vendors was found in all children. $78 \%$ children residing in area $>10$ years and $66 \%$ children attending school for $>5$ years had a below average developmental score. Blood lead levels correlated significantly with increasing age and length of stay in this area.

\section{Introduction}

Sri Lanka does not have a screening programme for lead exposure. However, concerns have been expressed regarding blood lead levels of children living in the city of Colombo ${ }^{1}$.

Long term exposure to even low levels of lead affects cognitive development of children ${ }^{2,3}$. We report on the cognitive development of a cohort of lead exposed city dwelling children and compare it with their duration of stay in this traffic congested area and their blood lead levels.

\section{Objective}

To study the cognitive development of children exposed to lead in Colombo.

\footnotetext{
${ }^{1}$ Senior Lecturer in Paediatrics, Faculty of Medicine, University of Colombo, ${ }^{2}$ Demonstrator, Department of Paediatrics, Faculty of Medicine, University of Colombo.
}

(Received on 20 November 2002)

\section{Design}

A cross-sectional descriptive study.

\section{Study population}

The study population consisted of 50 apparently healthy children aged 1-15 years who had lived since birth within a radius of $0.5 \mathrm{~km}$ from Borella junction in the city of Colombo. Their blood lead levels ranged from $1.6-13.5 \mathrm{mg} / \mathrm{dl}$ at the time of study. Mean blood lead levels in relation to age were:

$$
\begin{array}{rr}
<5 \text { years } & 4.3 \pm 1.9 \mathrm{mg} / \mathrm{dl} \\
5-10 \text { years } & 5.5 \pm 1.3 \mathrm{mg} / \mathrm{dl} \\
10-15 \text { years } & 6.7 \pm 1.8 \mathrm{mg} / \mathrm{dl}
\end{array}
$$

\section{Method}

The presence of environmental and behavioural risk factors for lead exposure were assessed using an interviewer administered questionnaire (Table 1).

Table 1

Risk factors for lead exposure in children

\section{Environmental risk factors}

Vehicular congestion

Lead lined water tanks

Lead piping

'Old' paint in homes

Proximity of home to road

Surface water drains

Lead-linked parental occupations

Lead-linked industries

\section{Behavioural risk factors}

Purchase of edibles from roadside vendors

Food preparation in glazed pottery/ceramics

Roadside playing

Chewing or sucking pencils

Habitual hand-mouth activities

Use of traditional cosmetics ('surma')

The development and cognitive abilities of all 50 children in study population were assessed. Modified 
Griffith Development scales were used to assess 1-6 year olds. Gross motor, eye hand co-ordination, hearing and speech, social skills and performance were assessed to calculate developmental quotients as a percentage of:

developmental age in months

chronological age in months

Children over 6 years had their number and reading skills assessed using age appropriate school textbooks and a validated scoring system ranging from 0 6. Ability to read a paragraph, identified from second lesson of prescribed text-book, was judged 'good', 'correct but hesitant', 'incorrect' or 'unable' and a score of 3, 2, I or 0 awarded accordingly. The last sum in each of the first three lessons was tested and one mark awarded for each correct answer. Adequate time was provided to think, work and write the answers. Final grading score comprised a combination of the reading and number scores, ranging from 6 to 0 . A combined score of 6 or 5 was rated above average', a score of 4 or 3 'average' and a score $0-2$ 'below average'. Scores obtained were compared with chronological ages and blood lead levels.

\section{Results}

The children were all of poor socioeconomic backgrounds and lived in an environment with risks of lead exposure. Close proximity to traffic congested highways and surface water drains were common to entire cohort studied. Purchase of food from roadside vendors was found in all 50 children.

School aged children were from three different schools in locality. We did not find behavioural or neurological abnormalities. Developmental/cognitive assessments showed the following results:

Of 13 children residing in this area for $>10$ years, 10 (78\%) had a below average developmental score. Children who lived 5-10 years in the area had significantly higher developmental scores $(\mathrm{p}<0.01)$.

In relation to number of years of schooling, $66 \%$ of children who attended school for $>5$ years had a below average developmental score whereas $80 \%$ of children who attended school for $<5$ years had above average developmental scores $(\mathrm{p}>0.05)$.

Decrease in cognitive scores correlated significantly with increasing age and length of stay in area. Blood lead levels also showed a significant correlation with age and duration of stay in area ${ }^{1}$.
Hand to mouth activities and playing by roadside or in parks adjacent to busy highways were behavioural risk factors that related significantly with below average developmental scores.

\section{Discussion}

Children have a higher lung deposition and gut absorption rate of lead than adults. They inhale a larger volume of air per unit body weight and hence are more vulnerable to lead in air.

Area of residence of these children was in close proximity to a junction which was under construction at time of this study. 5 roads with heavy traffic congestion met at this junction.

$90 \%$ of lead in city air is from vehicles that burn leaded petrol $^{4,5}$. Air pollution contaminates soil and lead persists in environment for a considerable period of time even after removal of lead from petrol.

Damage caused to developing central nervous system by lead is well known ${ }^{3,6}$. The cohort of children we studied all had assayable lead levels in their blood as estimated by Occupational Hygiene Division of Department of Labour, Colombo using atomic absorption spectrometry ${ }^{1}$. Our finding that developmental and cognitive scores had decreased with increasing age may have contributory factors apart from lead, since cognition is affected by many variables such as social, educational, environmental and medical factors. For example even noise levels around schools influence cognition $^{7,8}$

However, based on our finding that cognitive abilities were adversely affected in socially disadvantaged children attending three separate schools in an area in the city with heavy traffic congestion; and that it correlated to length of stay in area; we recommend closer scrutiny on effects of lead on cognitive development in urban children in Sri Lanka. Risk of lead exposure remains even after leaded petrol is discontinued. We hope the public health authorities will undertake screening programmes for excess lead in children because effects of lead are neither immediate nor obvious.

\section{References}

1. Amaratunge S, Sumanasena S P, Hubert H D M, Senanayake Manouri P. Blood lead levels of children living near Borella junction. Ceylon Medical Journal 2001; 46:111.

2. Good M 1. Long term effects of exposure to low doses of lead in childhood. New England Journal of Medicine 1991; 324:415-8. 
3. Needleman H I, Schell A, Bellinger D, Levinton A, Allred E N. Long term effects of exposure to low doses of lead in childhood, an 11 year follow up report. New England Journal of Medicine 1992; 322: $83-8$.

4. Read R C, Green M. Internal combustion and health. British Medical Journal 1990; 300: 761-2.

5. Romieu I. Urban air pollution in Latin America and the Carribean: Health Perspectives. World Health Statistics Quarterly 1990; 43:153-67.
6. Fulton M. Influence of blood lead on ability and attainment of children in Edinburgh. Lancet 1987; 2:1221 -6.

7. Sanz S A, Garcia A M, Garcia A. Road traffic noise around schools: a risk for pupils/ performance? International Archives of Occupational and Environmental Health 1997; 65(3): 205-7.

8. Lane S R, Meechara W C, Jet noise at schools near Los Angeles International Airport. Journal of Acoustical Society of America 1974; 56:127-31. 
